\title{
Instruments of Urban Planning in Algerian City: Reality and Challenges
}

\author{
Mohamed Gherbi \\ Department of Architecture, Faculty of Science and Technology, University of Tebessa, Tebessa 12007, Algeria
}

\begin{abstract}
The year 1990 marks a line of rupture in the history of Algeria in general by the fundamental changes that have occurred, especially in the fields of urbanism and the land use planning, which has an important impact on space of the city and its environment. However, the absence of directives based on the reality of upstream territories and sometimes the conflict and the weakness of the instruments created at different levels: national, regional and local, have accelerated the galloping development of urbanization (the irrational consumption of land reserves inside and around the city), often at the expense of the agricultural land. On the other hand, the involvement of new actors in the production of the framework built in the Algerian town was made without compliance with the rules of architecture and urbanism contained in the build permit and in the MPU (Master Plan of Land Use and Urbanism) and the SOP (Soil Occupation Plan) approved. The analyses conducted in the cities such as the capital Algiers and Setif illustrate this situation well. This article presents these situations of paradox, identifies their causes and suggests the recommendations to implement in the framework of studies and actions to take, to correct and regulate their mutations.
\end{abstract}

Key words: Architecture and urbanism of the city, building permit, national and regional levels, MPU, SOP, regulation of mutations.

\section{Introduction}

According to the Ministry of Land Use, Environment and Tourism of Algeria, nearly 45\% of the population still live on an area of 30 million ha. The majority of this area is concentrated in the coastal zone by less than $2 \%$ of the land area while the rest of the country is practically empty [1].

This has prompted authorities to create and implement a battery of tools ${ }^{1}$. It is composed of four

Corresponding author: Mohamed Gherbi, lecturer, research fields: urban planning, architecture, planning territory instruments, heritage protection, preservation of environment and civil engineering. E-mail: archi_teb@yahoo.fr.

${ }^{1}$ Placed above MPU (Master Plan of Land Use and Urbanism) and SOP (Soil Occupation Plan), the instruments created from global to local are: the NS (National Scheme), the DMSC (Development and Management Scheme for the Coast), the NASCD (National Action Scheme to Combat Desertification). This instrument was invented because the effects of climate change have a significant impact on Algeria where a large part of the country is covered by the desert of Sahara, and desertification is already a major problem. The RS (Regional Scheme of the Land Use Planning), the WP (Wilayal Plan of the Land Use) [2] and finally, the DSMA (Directing Scheme for Metropolitan Areas) are able to replace the WP especially for big cities such as Algiers, Oran and Annaba and where problems of the land use and environment arise with acuity. levels in order to design and implement a coherent development of the entire territory of Algeria, from global to local level in the framework of globalization and sustainable development.

Represented by NS, DMSC, RS, NASCD and DSMA, they have a mission to cover the whole country by dividing it into homogenous zones delineated on the basis of the intersection of several factors: socio-economic, cultural, potentialities and perspectives of the development, technics, geomorphological, etc. [3]. Because as it was practiced before 1990, the division of the territory of the country was found only on the criterion of administrative division which ignores these settings.

These schemes are developed for the long term (15-20 years) and are flexible. Their flexibility gives them the opportunity to adapt to desired trajectories of development and circumstances of the moment if they are based on sound analysis and cross sectional studies well-conducted.

Cf. Law 01-20 and Law 90-07 (all names of instruments and plans are translated from French by author). 
The national scheme which is the first level of the hierarchy instrumental is intended to provide guidance and features of the national policy of the land use and its development in the future. It was approved in 2005 and covers the period up to 2025 .

The large sensitive areas of the Algerian space like the coastal, the plains of the highlands form the intermediate scale, are supervised by special schemes: DMSC and NASCD.

The regional scale and the third level are formed by the RS which are under study and only very few of them are approved. The WPs still have ambiguous status [2] because they are marginalized and the DSMAs only concern large and important cities like Algiers, Oran, Constantine and Annaba.

The fourth and final levels of the instrumental hierarchy are represented by the MPU as SOP [4]. The SOP acts under the direction and guidance of the MPU and within the perimeters that it defines.

The MPU has a double territorial dimension: on the one hand, it concerns the space of the commune and is based on the administrative division as limit of his intervention; but on the other hand, it concerns inter-communal scale when the issues and common interests of the municipalities concerned are necessary either inside the communes of the same wilaya ${ }^{2}$ or of different wilayas.

Theoretically, this approach facilitates the design and implementation of a profitable and harmonious development for the entire territory of the country.

\section{Limits of the Institutional Framework and Conflicts of Scales}

Depending on the approach from global to local, new institutions are being proposed for the development to manage these diagrams and plans, and to strengthen the role of the regulator following state to the involvement of new actors.

At the national level, the NCSD (National Council

\footnotetext{
${ }^{2}$ Wilaya is an administrative division that contains a set of communes. Each commune may have one or more cities and villages.
}

for Sustainable Development of the Territory) has been created in order to take care of the national scheme. Concerning the regional level, nine RC (regional conferences) have been decided and adopted to manage the RS. They represent nine new planning regions identified by the division that takes into consideration all the commonalities shared by these regions as part of the national land use policy.

The geography of these planning areas is changing and varies from territories included in one wilaya to those of the several wilayas, even large areas like the southern Algeria.

These new planning areas are not founded on the existing administrative boundary established on the last communal remodeling in 1990, but on a new approach. However, they do not have the real decision-making power because and according to the Algerian legislature, the principle of decentralization of the effective power stays maintained centrally.

Therefore, how and by what procedures, the directives and guidance from the NS, DMSC, RS and NASCD once approved, can be transmitted at the local level-the concerned wilayas and their communes and cities before the development of their local development plans: MPU and SOP? Because in practical terms, these schemes are not yet completed and approved with the exception of the national scheme. But NS cannot act alone on the reality and supervises the local level.

The consequence at the downstream is that MPU and SOP are unable to specify the certainties even if they offer possibilities. For instance, they cannot tell the time for such an activity if it can cease to be profitable in a few months and disappear. They also do not have the capacity to confirm if a large urbanized area will be urbanized in the short or long term or if a programmed infrastructure will be delayed for years or canceled due to the budget savings [5, 6].

Additionally, the inter-communal MPU stays inefficient on the reality despite that it came to complete the instruments of land use operated at the 
regional level because of the lack of the inter-communal institutions and the absence of a competent steering committee.

Therefore, involving the CPA (communal popular assemblies) concerned by this scale to the studies of MPU, for instance, without the organizational approach and distribution of the skills, transforms these efforts to fail, especially in the emergency programs (presidential programs) that are imposed, or in the conflicts of political parties representing local society.

These CPA are not formed or at least, not yet accustomed to working together within the framework of inter-communal cooperation when it concerns the issues and common interests. The field is thus, left free to uncoordinated and incoherent sectoral interventions in time and/or in space during the implementation of the SOP and MPU.

The absence of the strategic guidance from upstream makes the instruments downstream inefficient to control changes in cities, and that is why they are frequently revised, or renewed, but never respected.

The analysis of Setif and Algiers confirms the situation where a significant loss of lands was recorded as a negative balance [7-9].

\section{Setif and Its Development}

The city of Setif lives the problem of the deficit of lands for two decades, and this difficulty is due to several endogenous and exogenous factors. The non-security situation that lived the country has encouraged a significant exodus of population towards the city coming from major cities like Algiers and Boumerdes and the surrounding areas. At that time, Setif has recorded 1 million inhabitants according to the statistics of the electoral lists of 1995-1996, but later, the number has decreased.

Due to its geostrategic position and its area of influence, its power of attraction continues to polarize the entire region of the highland for various functions and important infrastructures available in the city. However, the soils in the industrial zone located in the south have a relative saturation while the lands in the periphery of the city are private with high agricultural value. This situation constitutes the major obstacle for the needs of the city in the medium and the long term.

Faced with this situation, the MPU Setif of 1997 has evaluated nearly 1,600 ha to satisfy the needs of the city in the next 25 years, but it also reported that the lands located in the east, beyond the city limits, are classified as agricultural lands of high yield.

As inconvenient, the MPU was limited only to densify and restructure the existing urban spaces. It had the intention to protect the agricultural lands and to avoid the mistakes made in the past, as it was the case for El Hachemi subdivision located north-east of the city. This subdivision for individual housing had devoured 187 ha of the agricultural lands of high potentiality.

Unfortunately, the guidelines of the MPU have not been respected where an important program of habitat was implemented at the east of the city. This has inevitably led the revision of the MPU in 2002 in order to regulate these actions.

And normally, in the case of the transfer of the lands of high agricultural potentiality to the category of urbanized land, the authority should be authorized by the intervention and the review of the NPA (national popular assembly). It should be done through a legislation that specifies the technical and financial constraints accompanying the transfer operation, but it was not the case.

URBAS $^{3}$ had proposed a draft to solve the lack of land in Setif, through the deferral of future urbanization of the city towards the surrounding communes like Ain Arnat in the west, Ouled Saber in the east, El Ouricia to the north, Mezloug, Ain Abessa and Guedjel to the south. These are considered as balance poles and centers to promote.

This suggestion has the aim to satisfy the needs in

${ }^{3}$ It is a public company responsible for study and achievement in urbanism in Setif. 
spaces of Setif for the industrial, tertiary and agricultural activity, but the level and structure of this intervention (the inter-communal MPU) have never seen the day for several reasons. And finally, the suggestion was rejected.

That is why the revised MPU provides that, on the 1,600 ha for Setif, $60 \%$ of this area must come from agricultural land.

The DAS (the direction of agricultural sector) expressed strong reservations about the MPU which were not taken into account. The city has provided approximately 410 ha within its perimeter: 300 ha at Gaoua in the north and 110 ha on the set of Chouf Lekdad in the west. This last site has received the extension program of the new pole of University of Setif.

The abusive consumption of the lands registered before the expiration of the term decided by the MPU of Setif, the revisions of the MPU for regularizing the anticipated situations, and its inability to preserve agricultural land in particular, have confirmed that the MPU is unable to impose its requirements.

According to the Laws 90-29 and 90-30, only the instruments of land use and urbanism (due to their role of protection of land use), like MPU and SOP, have the power to allow transfers of land use from the agricultural use to urban use and regulate the terms of land use [4, 10]. Unfortunately, this was not the case in practice.

The high urban pressure has led to a diffuse urbanization and has participated in the transgression of the UAA (useful agricultural area), while the absence of the protection of peri-urban agriculture and the ambiguities in the law related to land orientation, have encouraged the authorities to marginalize agricultural activities.

The most coveted lands by the urbanization in Setif are agricultural lands of the private domain of the state, operated by the CAE (collective agricultural enterprises) and IAE (individual agricultural enterprises). It is difficult to mobilize the lands of the private properties when the compensation fixed by the state for the farmers is insignificant.

This situation has created tensions and conflicts that block or delay the achievements of projects initiated by the state. However, the land transactions operated between the private properties are made in discretion and are often encouraged by the strong speculation. It especially concerned lands in the constructability areas and near the roads, or in already built areas, where the prices are becoming exorbitant.

\section{Challenges for Algiers}

The case of Algiers is representative and resembles to Setif. It is a city that continues to exercise its power of attraction on its region and on the hinterland.

Algiers was covered by different plans and schemes: the GGP (The General Guidance Plan), the MPU (The Master Plan of Urbanism (the old plan and the new one)), the MUD (The Major Urban Design) and currently the MPU. These plans could not control or stop the high pressure of urbanization which continues to consume important lands, often of very high agricultural values like the plains of Metidja.

The reason is the missing of guidance from the upper level of Algiers town, and even if they exist, they were never been respected.

On the other side, all the studies included in these plans and schemes insist on that because the design of development of Algiers cannot be taken in its current administrative boundaries but must be sought in the place of Algiers compared to its region.

The dynamic of Algiers is partly connected to external phenomena, and ignoring the power of these phenomena will induce the non-effectiveness of the public intervention and the documents of urbanism and land use to regulate these dynamics.

For the design of the development of Algiers, two options are offered: the use of metropolitan approach in the framework of the DSMA, or the use of the inter-communal approach in the framework of an inter-communal MPU. 
The implementation of these two approaches should be well clarified, to avoid the risk of the conflict of scales intervention and to well solve the problems for the city beyond the communal boundary not yet developed.

In this sense, it is recommended first to restudy the urban frame of the whole of the region of Algiers and its change to adapt to the new exchange conditions imposed by globalization and not only by its metropolitan area. The urban features of Algiers will be redefined in the change of the general context and the territorial reconfiguration.

And secondly, to explore the possibilities of postponing urbanization on sites capable of forming poles of balance in the framework of sustainable development because the imbalances created in the national metropolis will directly affect the whole of the urban frame.

Finally, the diagram of the urban area of Algiers will be deducted from the region studies of Algiers and of the synthesis made of the already elaborated GGP, MPU and MUD.

The local and central authorities aspire to give for Algiers in future the image of an international metropolis in addition to its role as the national capital. But how it could be possible while the policy instruments for its development are insufficient or inadequate with this ambition?

This leads to better anchor the local planning in the regional and the national land use, and to change the design of the intervention of public structures by a new orientation of urbanism. Therefore, it concerns to "guide" the transformations, to "control" the operations, to attract, to convince and to seduce.

\section{Conclusions}

The harmonious development of Algerian cities cannot be designed only by the presence and implementing real and serious guidance emanating from the global approach and the local planning of the territory.
At the local level, the developed zonings allow the easy identification and the framing actions to implement but must also mention the financial capacities of the territories in question because relying only on the equalization system that the state applies to regions in difficulty, may compromise the future of these territories.

The issues and the complexity of questions in the politics of Algerian cities often cross the borders of the zonings inside as outside the cities as well the borders of the communal boundaries.

It is recommended then to define the necessary perimeters for the common development of the cities in order to ensure the protection and rational use of their land in the short, medium and long terms.

This implies not to neglect these borders, to think about these areas in the same way done for the zones inside the boundaries of a given territory, and to reformulate the concepts of limits and scales employed today in the design of the land use policy.

Therefore, it is an innovation to promote and implement to ensure the proper functioning of all the land use and urbanism instruments able to supervise the development of cities.

\section{References}

[1] EU (European Union). 2010. "European Neighbourhood and Partnership Instrument." National Indicative Programme of Algeria: 2011-2013. Accessed July 13, 2011. http://ec.europa.eu/world/enp/pdf/country/2011 enpi_nip_algeria_en.pdf.

[2] General Secretariat of Government. 1990. "Law 90-09 of April 7, 1990. Wilaya." Official Journal of Republic of Algeria 15: 434-45.

[3] General Secretariat of Government. 2001. "Law 01-20. Land Use and Sustainable Development of the Territory." Official Journal of Republic of Algeria 77: 15-25.

[4] General Secretariat of Government. 1990. "Law 90-29 of December 1, 1990. Land Use and Urbanism." Official Journal of Republic of Algeria 52: 1408-15.

[5] Gherbi, M. 2012. "Problematic of Environment Protection in Algerian Cities." Elsevier 18: 265-75. Accessed June 9, 2012. http://www.sciencedirect. com/science/article/pii/S1876610212008089.

[6] Gherbi, M. 2013. "From Local to National, Which 
Appropriate Instruments for Land Planning in Algeria?." Presented at Geoscience for Sustainable Development, 3rd International Conference, University of Tebessa.

[7] Gherbi, M. 2010. "Points of Thought for Effective Land Strategy in Algeria, in the Urban Land, Issues and Backgrounds.” Presented at the Urban Land: Stakes and Horizons, 1st International Conference, University of Batna.

[8] Gherbi, M. 2004. "Algiers and the Instruments of Development.” Presented at Algiers in Front of the New
Challenges of the Urbanization, International Conference, Algiers.

[9] Gherbi, M. 2001. "Proposal of Methodology of Soil Occupation Plan on a Site to Urbanize, Case of $\mathrm{SOP}_{33}$, Gaoua, Setif.” Thesis of magister, School of Architecture and Urbanism of Algiers, EPAU (Polytechnic School of Architecture and Urbanism).

[10] General Secretariat of Government. 1990. "Law 90-25 of November 18, 1990. Land Orientation.” Official Journal of Republic of Algeria 49: 1332-9. 